\title{
Serum endothelin concentrations in workers exposed to vibration
}

\author{
K T Palmer, H Mason
}

\begin{abstract}
Objectives-Endothelin $1\left(\mathrm{ET}_{1}\right)$ is one of a newly discovered family of potent naturally occurring vasoconstrictors produced by the endothelium. A few publications indicated that the peptide may have a role in idiopathic Raynaud's phenomenon and Raynaud's phenomenon secondary to connective tissue disease. The aim of this study was to compare serum endothelin concentrations in people with vibration induced white finger (VWF) with those of controls exposed to vibration, and unexposed (pure) controls.
\end{abstract}

Subjects and methods-Male volunteers from a stonemasonry, two quarries, and an insurance company were classified by questionnaire and clinical examination into men with VWF (cases, $n=31$ ), exposed controls $(n=22)$, or pure controls $(n=36)$. All subjects were asked to provide two venous blood specimens: a baseline sample after a period of warm equilibration (30 minutes seated in a warm room and 20 minutes with both hands immersed in a water bath at $37^{\circ} \mathrm{C}$ ); and again after cold challenge (both hands immersed in a water bath at $6^{\circ} \mathrm{C}$ for six minutes). Serum concentrations of the 21 amino acid peptide endothelin ET $_{1-21}$ were measured by radioimmunoassay.

Results-Baseline concentrations of ET $_{1-21}$ were found to be lower in cases (mean = $12.2 \mathrm{pmol} / \mathrm{l})$ than in the two control groups (mean $=14.7 \mathrm{pmol} / 1$ in exposed controls; mean $=14.3 \mathrm{pmol} / 1$ in pure controls). Among cases there was a broad inverse relation between severity, as measured by the Griffin blanching score, and baseline $\mathbf{E T}_{1-21}$ (Spearman rank correlation coefficient $-0.58, P<0.001)$. Cold challenge provoked an overall rise in ET $_{1-21}$ in all groups, but larger and significant mean absolute and percentage rises were found in cases $(4 \cdot 1 \mathrm{pmol} / 1$ and $54 \%)$ than in the control groups $(2.6 \mathrm{pmol} / 1$ and $21 \%$ in exposed controls; $1.5 \mathrm{pmol} / 1$ and $20 \%$ in pure controls). Similar but more obvious differences occurred when controls were compared with those cases who gave a more severe history of disease (Griffin blanching score $\geqslant 24$ ) and those cases found to blanch after cold challenge. In these case subsets baseline ET $_{1-21}$ was nearly $50 \%$ lower than for controls and a four and a half to fivefold greater percent- age rise in $\mathrm{ET}_{1-21}$ occurred upon cold challenge. Differences were significant. Close matching for age and smoking did not alter the principal findings. No significant differences, whether in baseline or cold response, were found between unexposed and exposed controls.

Conclusions-Baseline findings seem to contradict various published series and attempts are made to reconcile the differences. It is suggested that a lower baseline $E_{1-21}$ in cases may result from a disease compensation mechanism or damage effect. The large relative rise in serum ET $_{1-21}$ when cases are cold challenged may contribute directly or indirectly to vasospasm, but a simple mechanism is unlikely and interpretation is limited by the absence of measurements of forearm blood flow.

(Occup Environ Med 1996;53:118-124)

Keywords: vibration; endothelin; vibration induced white finger

Vibration induced white finger (occupationally induced Raynaud's phenomenon secondary to hand arm vibration) is characterised by spasmodic blanching of the digits, especially in response to cold. ${ }^{1}$ The mechanisms that produce blanching are imperfectly understood despite much research: however, both vasospasm and fixed obstruction of the lumen of the digital vessels may operate, to a greater or lesser extent. ${ }^{2}$

In 1973 Nerem suggested that sheer stress induced by vibration could provoke damage to the endothelial wall and accompanying blood abnormalities. ${ }^{3}$ Other workers have described abnormal blood rheology in hand arm vibration syndrome including abnormalities of platelet function, ${ }^{4}$ blood viscosity, ${ }^{5}$ and plasma fibrinogen, ${ }^{6}$ but the role of the endothelium has been little explored.

By contrast, in research physiology, the vasoregulatory activity of the endothelium has been closely studied, and in the past decade many endothelium derived vasodilator (relaxing) factors (EDRFs) and endothelium derived constrictor factors (EDCFs) have been discovered and investigated during health and disease. ${ }^{78}$ Among these, the novel 21 amino acid peptide endothelin $\mathrm{ET}_{1-21}$ has provoked most excitement because of two very special properties: extraordinary vasoconstrictor potency (log orders of magnitude greater 
than for other EDCFs); and an unusually prolonged time course of activity. ${ }^{9}$

Raised concentrations of endothelin have been found after cold challenge ${ }^{10}$ and in a range of vascular diseases. ${ }^{11-14}$ Working hypotheses suggest that endothelin causes, or contributes to, pathological vasospasm, and is itself often produced as a result of endothelial damage.

Despite its plausible credentials, there have been relatively few peer reviewed reports concerning the mechanistic role of endothelin in Raynaud's phenomenon. Zamora et al, ${ }^{15}$ studying women with primary Raynaud's phenomenon, reported a threefold increase in baseline (warm equilibration) concentrations and an exaggerated cold response in seven cases compared with matched controls. A second group of workers reported similar but less clear cut findings in a population with secondary Raynaud's phenomenon of mixed, non-occupational origin. ${ }^{16}$ More recently histochemical investigations have highlighted a general depletion of vasoactive peptides in the cutaneous nerve fibres supplying the fingers of patients with VWF. ${ }^{17}$ The only occupational study of serum endothelins compared riveters with matched controls: workers exposed to vibration, some of whom had VWF, were found to have a slightly lower baseline $\mathrm{ET}_{1} .^{18}$ Cold responsiveness was not examined.

Interpretation of these limited publications is hampered by differing methods in-for example, temperature control, sampling and immunoassay, population mixes, case definition, and allowance for potential confounders-still leaving open some questions of importance to the occupational physician.

\section{STUDY OBJECTIVES}

The aim of the present study was to examine the relation between serum $\mathrm{ET}_{1}$ and long term hand arm vibration. In particular, answers were sought to the following questions.

(1) Are there differences in the baseline (warm equilibration) concentrations of $\mathrm{ET}_{1}$ when cases of VWF are compared with controls? If so, do the differences correlate with severity of disease?

(2) Are there differences in the baseline concentration of $\mathrm{ET}_{1}$ in people exposed to vibration compared with unexposed people? If so, do the differences correlate with degree of exposure to vibration?

(3) Do serum endothelins rise in response to cold challenge? If so, are there differences in response between VWF cases and controls, and can these differences be related to severity of disease or manifestations of blanching? Are there differences in response between exposed and non-exposed groups and if so, can the differences be related to degree of exposure to vibration?

The study design and protocol were in agreement with the principles of the Helsinki declaration on biomedical research 1964 and 1989 and were reviewed by the Health and Safety Executive's Research Advisory Team. Participants gave their written informed consent to all procedures.

\section{Methods}

STUDY POPULATIONS

In 1990 the Health and Safety Executive received a series of case reports of VWF under the Reporting of Injuries, Diseases, and Dangerous Occurrences Regulations (RIDDOR) 1985. The cases arose from two working populations on the Isle of Portland in Dorset: stonemasons and quarrymen. Exposure to vibration in these trades has traditionally been high.

In the stonemasons, banker and line masons hand worked limestone blocks with chipping hammers and other tools with hazardous vibration characteristics. Other job descriptions entailed occasional use of air powered tools-for example, plane machine operatoror previous experience as a mason-for example, sawyer foreman-and job mobility was such that few men had escaped significant occupational exposure to vibration.

Quarrymen extracted the large limestone blocks used in the masonry and in dimensional construction work. The dimensional quarryman's skill lay in identifying fault lines in stone. A line of holes was then made in the stone with a consolidated pneumatic rock drill and wedges were driven into the holes with a consolidated pneumatic road breaker. Eventually the stone split. This traditional method has been used for more than one hundred years. In the extraction of dimensional stone much effort is expended in preserving the integrity and shape of the extracted block and the relative precision of the operation has until recently delayed attempts at mechanisation. Frequency weighted vibration exposures in excess of $20 \mathrm{~ms}^{-2}$ root mean squared (rms) have been common over the years, although conditions have since improved. Persistence of traditional methods and the unusually low job mobility of Portland workers provided a cohort of subjects with well documented high lifetime occupational exposures to vibration.

All male employees from a stonemasonry and two quarries were invited to participate. Out of 69 workers $55(80 \%)$ agreed, but two were ineligible according to defined study criteria-namely clinical diseases which were known to cause secondary Raynaud's phenomenon or otherwise independently affect serum $\mathrm{ET}_{1}$ and this led to an overall response rate of $77 \%$. Also, owing to the sparse number of people (five) without occupational exposure to vibration, the non-exposed (pure) control group was supplemented by an age stratified random sample of male employees from a Hampshire insurance company. All respondents completed a questionnaire, and all those fulfilling inclusion criteria participated. They provided a further 31 controls with one exclusion (a response rate of $21 \%$ ).

\section{STUDY METHODS}

All participants were seen on two occasions in the summer. On the first, a diagnostic questionnaire was given by a trained nurse or doctor and was accompanied by a clinical examination of the hands and upper limb pulses; and a single blood pressure reading from the right 
arm was taken when sedentary and rested. On the basis of this assessment participants were later classified as cases, exposed controls, pure controls, or were excluded according to predetermined criteria applied by a single observer. Severity of disease and degree of exposure to vibration were also assessed.

Second sessions took place before work on Monday mornings, allowing a weekend break from use of vibratory tools. Participants were asked to abstain from smoking on the day of the study and to limit alcohol consumption to two units on the preceding evening.

At their second attendance participants sat for 30 minutes in a warm room $\left(18\right.$ to $23^{\circ} \mathrm{C}$ ) and were then randomly allocated to one of three identical research stations, comprising a researcher with thermostatically regulated warm and cold water baths. Subjects first immersed their hands in a warm water bath set at $37^{\circ} \mathrm{C}\left( \pm 5^{\circ} \mathrm{C}\right)$ for 20 minutes. At the end of the warm equilibration period participants had their oral temperature measured: all values fell within the normal physiological range for core body temperature. A $10 \mathrm{ml}$ venous blood sample was taken from the antecubital vein, the arm conventionally selected was, in cases with asymmetric disease, the side worse affected; in cases with disease of equal severity in both hands, and in non-cases, from the side of the dominant hand. This warm equilibration (baseline) blood sample was drawn into an EDTA tube, mixed and immediately centrifuged at $4^{\circ} \mathrm{C}$ then separated, and the plasma stored below $-15^{\circ} \mathrm{C}$ for later analysis.

Participants then placed both hands into a cold water bath at $6^{\circ} \mathrm{C}\left( \pm 1^{\circ} \mathrm{C}\right)$ for six minutes. The duration of the challenge was decided on the basis of a small pilot study in forestry workers. A second blood specimen was taken from the same arm immediately after the cold challenge and processed in the same way as the baseline specimen. Subjects' hands were quickly dried and evidence of blanching sought. Clinical observations were recorded and where possible photographed.

ASSAY

Several protocols exist for the measurement of $\mathrm{ET}_{1}$ and ET like immunoreactivity. ${ }^{15}$ 19-21 Samples in this study were analysed with a protocol and assay system to specifically measure $\mathrm{ET}_{1-21}$ (RPA 555, Amersham International, UK). This assay system is

Table 1 Demographic and exposure differences between case and control study groups

\begin{tabular}{|c|c|c|c|}
\hline & $\begin{array}{l}\text { Cases } \\
(n=31)\end{array}$ & $\begin{array}{l}\text { Exposured controls } \\
(n=22)\end{array}$ & $\begin{array}{l}\text { Pure controls } \\
(n=36)\end{array}$ \\
\hline $\begin{array}{l}\text { Age }(y): \\
\text { Mean (SD) } \\
\text { Range }\end{array}$ & $\begin{array}{l}44 \cdot 7(13 \cdot 3)^{\star} \\
16-63\end{array}$ & $\begin{array}{l}33 \cdot 8(14 \cdot 7) \\
18-62\end{array}$ & $\begin{array}{l}43 \cdot 1(10 \cdot 7) \\
25-53\end{array}$ \\
\hline $\begin{array}{l}\text { Blood pressure: (mean }(\mathrm{SD})(\mathrm{mmHg})) \text { : } \\
\text { Systolic } \\
\text { Diastolic }\end{array}$ & $\begin{array}{c}129(17 \cdot 9)^{\star} \\
81(12 \cdot 0)\end{array}$ & $\begin{array}{r}116(15 \cdot 7) \\
75(14 \cdot 1)\end{array}$ & $\begin{array}{r}123(17 \cdot 0) \\
81(11 \cdot 4)\end{array}$ \\
\hline $\begin{array}{l}\text { Tool use (h): } \\
\text { Median } \\
\text { Range }\end{array}$ & $\begin{array}{l}24500 \dagger \\
2630-100800\end{array}$ & $\begin{array}{l}1650 \dagger \\
150-65200\end{array}$ & - \\
\hline $\begin{array}{l}\text { Smoking (\%): } \\
\text { Current smoker } \\
\text { Exsmoker } \\
\text { Non-smoker }\end{array}$ & $\begin{array}{r}14(45) \\
13(42) \\
4(13)\end{array}$ & $\begin{array}{r}6(27) \\
6(27) \\
10(46)\end{array}$ & $\begin{array}{l}12(33) \\
11(31) \\
13(36)\end{array}$ \\
\hline
\end{tabular}

\section{Results}

CASES AND CONTROLS

On the basis of the questionnaire 31 cases of VWF were identified, together with 22 exposed controls and 36 pure controls. All but one of these cases had a past or present job description of mason or quarryman. Among those with a history of VWF 14 out of 31 $(45 \%)$ blanched after cold challenge. The severity of cases was scored with the blanching score proposed by Griffin ${ }^{22}$ summed from the individual scores for each hand. Scores ranged from 1 to 60 , the modal and median scores were both 24 .

To examine the possible association between case severity and $\mathrm{ET}_{1}$ in the analysis of data two case subsets were defined: (a) those men with the worst case histories - arbitrarily taken as a Griffin blanching score of 24 or more (worst cases, $\mathrm{n}=14$ ); and (b) those who blanched under cold challenge (blanchers, $n=14$ ).

\section{DEMOGRAPHIC FACTORS}

Table 1 shows the major demographic factors for the study groups-age, blood pressure, smoking, and exposure-with estimated hours of tool use as a rough but convenient proxy. Differences were as anticipated: cases were older than exposed controls and had used vibrating tools for longer; older subjects had higher mean blood pressures; and were more likely to be smokers or exsmokers $\left(\chi^{2}\right.$ test: cases $v$ exposed controls, $\mathbf{P}<0.05)$. Differences were accentuated in the subset of severe cases who were older again (mean (SD) age for the worst cases $52(11.6)$; and for blanchers $47.6(12.9)$ ), and had greater mean and median tool use (median up to 39300 hours in the worst case group).

The demographic comparison between cases and pure controls was closer for age and 
Table 2 Baseline (warm equilibration) serum ET, levels in the study groups

\begin{tabular}{|c|c|c|c|c|c|}
\hline \multirow{2}{*}{$\begin{array}{l}\text { Baseline } \\
E T_{1-2 l} \\
\text { (pmol/l) }\end{array}$} & \multicolumn{3}{|l|}{ Cases } & \multirow{2}{*}{$\begin{array}{l}\text { Exposed } \\
\text { controls } \\
(n=22)\end{array}$} & \multirow{2}{*}{$\begin{array}{l}\text { Pure } \\
\text { controls } \\
(n=36)\end{array}$} \\
\hline & $\begin{array}{l}A l l \\
(n=31)\end{array}$ & $\begin{array}{l}\text { Worst } \\
(n=14)\end{array}$ & $\begin{array}{l}\text { Blanchers } \\
(n=14)\end{array}$ & & \\
\hline $\begin{array}{l}\text { Mean } \\
\text { Median } \\
\text { SD } \\
\text { SEM } \\
\text { Range }\end{array}$ & $\begin{array}{c}12 \cdot 17^{\star} \\
12 \cdot 99 \dagger \\
4 \cdot 3 \\
0 \cdot 77 \\
5 \cdot 99-20 \cdot 77\end{array}$ & $\begin{array}{l}10 \cdot 01^{\star \star} \\
9 \cdot 67 \dagger \\
3.57 \\
0.94 \\
5 \cdot 99-15 \cdot 72\end{array}$ & $\begin{array}{l}10 \cdot 73^{\star \star} \\
9 \cdot 67 \dagger \\
3 \cdot 93^{\star} \\
1 \cdot 05 \\
5 \cdot 99-16 \cdot 62\end{array}$ & $\begin{array}{l}14 \cdot 72 \\
15 \cdot 16 \\
2 \cdot 33 \\
0 \cdot 5 \\
12 \cdot 84-17 \cdot 41\end{array}$ & $\begin{array}{l}14 \cdot 26 \\
14 \cdot 36 \\
4 \cdot 5 \\
0 \cdot 75 \\
5 \cdot 74-24 \cdot 85\end{array}$ \\
\hline
\end{tabular}

${ }^{\star} \mathrm{P}<0.05 ;{ }^{\star \star} \mathrm{P}<0.01 ;+\mathrm{P}<0.02$ case $v$ both control groups.

blood pressure, although the blue collar group still contained a smaller proportion of non-smokers than the white collar insurance workers.

\section{BASELINE ET ${ }_{1}$ CONCENTRATIONS IN STUDY GROUPS}

The mean baseline in cases was lower than in either control group (table 2). The same was true when medians were compared. Differences were significant at the $5 \%$ level. The mean and median baseline $\mathrm{ET}_{1-21}$ in the subsets of worse cases and blanchers were even lower. Again differences were significant. The Spearman rank correlation coefficient between Griffin blanching score and baseline $\mathrm{ET}_{1-21}$ in cases was calculated and found to be $-0.58(P<0.001)$, further suggesting a broad inverse relation between baseline $\mathrm{ET}_{1-21}$ and case severity. No correlation between baseline $\mathrm{ET}_{1-21}$ and hours of use of vibrating tools was found among the cases.

The difference in baseline between exposed controls and pure controls did not reach significance. Nor was any significant correlation found between baseline serum $\mathrm{ET}_{1-21}$ and hours of use of vibrating tools in exposed controls.

\section{RESPONSE TO COLD}

Four men (one case, one exposed control, and three pure controls) failed to provide an adequate blood specimen after cold challenge. Table 3 summarises the cold response in the remaining subjects. An absolute rise in mean $\mathrm{ET}_{1}$ was found in response to cold in all groups. Larger absolute and percentage rises were found in cases than in controls, and the largest rises were found in the two subsets, worst cases and blanchers. The null hypothesis, that cold has no effect other than by chance on serum $\mathrm{ET}_{1}$, was tested. In cases and case subsets the null hypothesis was sufficiently unlikely that cold challenge seems to be associated with a rise in serum $\mathrm{ET}_{1-21}$; how- ever, the null hypothesis could not be rejected in controls. Similar percentage increases were seen in the control groups (about $20 \%$ ), but the mean rise in cases was two and a half times greater, that of the worst cases four times greater, and in those who blanched the average rise was nearly $100 \%$-almost five times greater than the response in controls. The difference between subsets and control groups was significant at the $1 \%$ level.

The SDs for percentage change were large in all groups, reflecting a wide variation in response. However, the $\mathrm{SD}$ for cases was nearly twice as great as that for controls. This difference was also significant (comparison of two variances, cases $v$ either control group: $P<0.01)$. Although relative change differed significantly between the groups, it should be noted that no significant differences were found when the values after cold challenge were compared. This arises because the values from cases started from a lower baseline but rose further.

\section{MATCHING}

The data point to clear differences between cases and non-cases, whether exposed to vibration or not. However, in view of the demographic differences between case and control groups an exercise in matching was undertaken to consider whether these differences were due to disease correlates, rather than disease status itself. Cases were matched against controls on a one to one pairing - the basis being the same smoking status and nearest age. To provide sufficient controls for a satisfactory match, all non-cases were considered as a single control group, with exposed and pure control subjects available equally for matching. The exercise was repeated three times, to provide matched control groups for the three case groups previously considered (all, worst, and blanchers). Fifty pairs were thus matched, with a complete match for smoking in all pairs and an age match of plus or

Table 3 Absolute and proportionate changes in serum $E T_{1-21}$ after cold challenge

\begin{tabular}{|c|c|c|c|c|c|}
\hline & \multicolumn{3}{|l|}{ Cases } & \multirow[b]{2}{*}{$\begin{array}{l}\text { Exposed controls } \\
(n=21)\end{array}$} & \multirow[b]{2}{*}{$\begin{array}{l}\text { Pure controls } \\
(n=33)\end{array}$} \\
\hline & $\begin{array}{l}A l l \\
(n=30)\end{array}$ & $\begin{array}{l}\text { Worst } \\
(n=14)\end{array}$ & $\begin{array}{l}\text { Blanchers } \\
(n=14)\end{array}$ & & \\
\hline \multirow{3}{*}{$\begin{array}{l}\text { After cold challenge } \\
\text { Mean (SEM) } \\
\text { Absolute change: } \\
\text { Mean (SEM) } \\
\text { Percentage change: } \\
\text { Mean (SEM) }\end{array}$} & $15 \cdot 86(1.08)$ & $16 \cdot 73(1 \cdot 36)$ & $15.98(1.59)$ & $17 \cdot 41(1 \cdot 50)$ & $15 \cdot 52(1 \cdot 11)$ \\
\hline & $4 \cdot 05(1 \cdot 36)^{\star \star}$ & $6.71(1.66)^{\star \star}$ & $5 \cdot 83(2 \cdot 35)^{\star}$ & $2 \cdot 64(1 \cdot 54)^{\mathrm{NS}}$ & $1 \cdot 51(1 \cdot 26)^{\mathrm{NS}}$ \\
\hline & $54 \cdot 3(17 \cdot 5)^{\star \star}$ & $86 \cdot 8(23 \cdot 6)^{\star \star} \dagger$ & $99 \cdot 3(32 \cdot 3)^{\star \star} \dagger$ & $20 \cdot 8(10 \cdot 4)^{\mathrm{NS}}$ & $20 \cdot 4(10 \cdot 0)^{\mathrm{NS}}$ \\
\hline
\end{tabular}

$\star \mathrm{P}<0.05 ;{ }^{\star \star} \mathrm{P}<0.01$, paired $t$ test (null hypothesis (after cold challenge $=$ baseline)); $\mathrm{P}<0.01$ cases $v$ both control groups: multiple mean comparison test. 
Table 4 Comparison of study findings after matching for age and smoking status

\begin{tabular}{|c|c|c|c|c|c|c|}
\hline & $\begin{array}{l}\text { All cases } \\
(n=24)\end{array}$ & $\begin{array}{l}\text { Matched } \\
\text { controls } \\
(n=24)\end{array}$ & $\begin{array}{l}\text { Worst } \\
\text { cases } \\
(n=12)\end{array}$ & $\begin{array}{l}\text { Matched } \\
\text { controls } \\
(n=12)\end{array}$ & $\begin{array}{l}\text { Blanchers } v \\
(n=14)\end{array}$ & $\begin{array}{l}\text { Matched } \\
\text { controls } \\
(n=14)\end{array}$ \\
\hline Age (y): & & & & & & \\
\hline Mean (SD) & $43 \cdot 1(14 \cdot 8)$ & $43 \cdot 6(12 \cdot 7)$ & $50 \cdot 7(11 \cdot 9)$ & $50 \cdot 2(11 \cdot 3)$ & $47 \cdot 6(12 \cdot 9)$ & $47 \cdot 1(12 \cdot 3)$ \\
\hline Range & $22-63$ & $21-63$ & $21-63$ & $21-63$ & $24-63$ & $23-63$ \\
\hline Systolic BP $(\mathrm{mm} \mathrm{Hg})$ : & & & & & & \\
\hline $\begin{array}{c}\text { Mean (SD) } \\
\text { Diastolic BP (mm Hg): }\end{array}$ & $128(19 \cdot 1)$ & $122 \cdot 3(18 \cdot 4)$ & $135 \cdot 1(17)$ & $124(13)$ & $130 \cdot 8(18 \cdot 1)$ & $122 \cdot 1(12 \cdot 1)$ \\
\hline $\begin{array}{l}\text { Diastolic BP (mm Hg): } \\
\text { Mean (SD) }\end{array}$ & $81 \cdot 6(12 \cdot 4)$ & $82(12 \cdot 4)$ & $81.6(10 \cdot 0)$ & $82 \cdot 2(6 \cdot 9)$ & $80 \cdot 6(10 \cdot 8)$ & $83 \cdot 4(6 \cdot 4)$ \\
\hline $\begin{array}{l}\text { Base line } \mathrm{ET}_{1}(\mathrm{pmol} / \mathrm{l}): \\
\quad \text { Mean (SD) }\end{array}$ & $11 \cdot 89 \underset{\star}{(4.45)}$ & $14 \cdot 91(4 \cdot 3)$ & $10.07(3.54)$ & $14 \cdot 34(5 \cdot 53)$ & $10 \cdot 25(\underset{\star}{4} \cdot 17)$ & $14.03(4.95)$ \\
\hline $\begin{array}{l}\text { Absolute change after cold } \\
\text { challenge in } \mathrm{ET}_{1}(\mathrm{pmol} / \mathrm{l}): \\
\text { Mean }(\mathrm{SD})\end{array}$ & $\begin{array}{c}4.51(8 \cdot 02) \\
\dagger\end{array}$ & $\begin{array}{c}2 \cdot 34(8 \cdot 14) \\
\text { NS }\end{array}$ & $\begin{array}{c}7 \cdot 09(6 \cdot 78) \\
\ddagger\end{array}$ & $\begin{array}{c}5 \cdot 39(9 \cdot 32) \\
\text { NS }\end{array}$ & $\begin{array}{c}5 \cdot 83(8 \cdot 8) \\
t\end{array}$ & $\begin{array}{c}1.53(6.37) \\
\text { NS }\end{array}$ \\
\hline $\begin{array}{l}\text { Proportionate change after cold } \\
\text { challenge in } \mathrm{ET}_{1}(\%) \text { : } \\
\text { Mean (SD) }\end{array}$ & $\begin{array}{c}59 \cdot 5(100 \cdot 6) \\
\ddagger\end{array}$ & $\begin{array}{r}26 \cdot 3 \text { (67) } \\
\text { NS }\end{array}$ & $\begin{array}{c}92.5(95.9) \\
t\end{array}$ & $\begin{array}{c}47 \cdot 6(71 \cdot 2) \\
+\end{array}$ & $\begin{array}{c}99 \cdot 3(120 \cdot 7) \\
\ddagger\end{array}$ & $\begin{array}{c}22 \cdot 4(56 \cdot 2) \\
\text { NS }\end{array}$ \\
\hline
\end{tabular}

$\star \mathrm{P}<0.05$, Paired $t$ test: null hypothesis (case $=$ matched control); $\ddagger \mathrm{P}<0.01, \dagger \mathrm{P}<0.05$, paired $\mathrm{t}$ test: null hypothesis (after cold challenge $=$ baseline).

minus one year in 43 of the 50 pairs.

Table 4 summarises the outcome of the matching exercise. Despite a close match for age and smoking, the findings were manifestly similar: a lower baseline $\mathrm{ET}_{1-21}$ in cases than controls, broadly associated with disease severity; greater absolute and percentage rises in cases than controls after cold challenge, with the largest rises in those worst affected; and the results of significance tests were similar. Hence, matching for age and smoking did not alter the principal findings.

\section{Discussion}

The current investigation has several potential limitations. Participants were volunteers, so it is necessary to ask whether such populations of convenience differ materially from randomly selected ones. In populations exposed to vibration there is no reason to suppose so: the overall response rate was good and the study populations, setting, and clinical findings were typical of those expected in VWF research based in industry. Among pure controls the situation is less certain; the response rate was lower and it is known, for example, that several volunteers were regular blood donors. Pure controls had to be recruited from a different working population and there were clear cut social class differences between groups. We know of no scientific literature about the effects of social class and geography on serum $\mathrm{ET}_{1-21}$, but the possibility exists that unknown confounders contribute to the differences found between cases and pure controls.

However, the study examined two control groups. Controls exposed to vibration were well matched with cases from the socioeconomic and geographical standpoint and the differences here were just as clear cut as for pure controls; furthermore, the two control groups, although drawn from different settings, provide remarkably similar results; finally the protocol excluded controls with diseases of known relevance and the most readily identifiable confounders (age, smoking, blood pressure) have been considered in the matched pairs analysis. So there are grounds for considering these demographic differences to be unimportant compared with the differences between health and disease.

Case definition gives further scope for classification errors and biases. The study used a questionnaire, predetermined diagnostic criteria, and classification by a single observer. This approach has the advantage of minimising within observer variation and ensuring a consistent classification scheme even though that might still cause misclassification.

The case definition was modelled on that of Gemne et al-namely "attacks of well demarcated, local blanching and accompanying numbness of the affected parts of the finger skin triggered by exposure to environmental cold ... with a distribution that agrees well with the strongest vibration exposure". ${ }^{23}$ Special emphasis was given to demarcation of colour change and a minimum duration of response. The definition insisted on tool use before the start of symptoms. This excluded obvious cases of primary Raynaud's disease. It may not have excluded every case of Raynaud's disease in a male tool user (5\% to $10 \%$ of men admit to occasional blanching of the fingers or thumbs), but the high prevalence of disease in the Portland populations makes it likely that relatively few men said to have secondary disease actually had primary.

Reliance on clinical history poses the additional problem that participants could make up or exaggerate symptoms for personal gain. However, it is worth emphasising that the effect of misleading case histories, misclassifications, and inaccurate grading of disease would be to make genuine differences between groups harder to detect. The differences described in this study seem to be sufficiently large and robust to stand out despite these problems. Furthermore, the broad relation between case severity and the findings adds weight to the data. Finally, the blancher subset was the group in which the diagnosis was most clear cut, a group that actually manifested the phenomenon of interest around the time that blood was drawn: findings broadly accorded with those with the worst case histories. These combined findings indicate that the problems of case definition have not influenced outcome. 
The baseline findings contradict those existing studies for Raynaud's disease and secondary Raynaud's phenomenon due to causes other than vibration, in which a raised baseline $\mathrm{ET}_{1-21}$ has been described ${ }^{1516}$ However, they accord with the only other study of $\mathrm{ET}_{1}$ in workers exposed to vibration, which examined variation within a shift in finger systolic blood pressure in riveters and age matched controls, and as a subsidiary enquiry, measured $\mathrm{ET}_{1}$ in a subset of non-smoking volunteers. ${ }^{18}$ Unfortunately the proportion of workers with VWF and the degree of success in control matching in the subgroup was not clearly specified, and the protocol did not include an assay after cold challenge, making direct comparison of results impractical. However, a lower mean baseline was described, as in this report.

The disparity is most likely to be accounted for by differences in methodology, especially the radioimmunoassay. The $\mathrm{ET}_{1-21}$ is secreted as a precursor $\left(E T_{1-38}\right)$ and then cleaved. Older assay techniques have measured ET like immunoreactivity, which may be a composite of immunologically related but physiologically discrete secretion moieties. The Amersham assay, which was also used in the study of riveters, ${ }^{18}$ has a very low cross reactivity for other cleavage fragments, and is effectively $\mathrm{ET}_{1-21}$ specific. The findings of different research groups can be reconciled if cases have raised serum concentrations of the precursor $\mathrm{ET}_{1-38}$ but lower serum $\mathrm{ET}_{1-21}$ at baseline, a hypothesis untested so far to our knowledge.

An inverse association between baseline $\mathrm{ET}_{1-21}$ and disease severity is an unexpected finding, given endothelin's known constrictor potential. However, $\mathrm{ET}_{1-21}$ is a complex agent with complex pharmacodynamics: depending on production pattern and the intrinsic tone of vascular beds it may act as a vasodilator ${ }^{24}$; it is known that $\mathrm{ET}_{1-21}$ is present in peripheral venous blood in concentrations several log orders of magnitude lower than those constricting isolated vascular rings; that $\mathrm{ET}_{1-21}$ potentiates noradrenalin and serotonin, and perhaps other agents too $^{25}$; and that there exists a complex balance between EDRFs and EDCFs, the details of which are only partially understood. At warm equilibration temperatures vasospasm is absent in all but the most severe cases, so there is no intrinsic reason for assuming a simple relation such as a raised $\mathrm{ET}_{1-21}$ under these conditions. Finally, the circumstances that regulate the cleavage of $\mathrm{ET}_{1-38}$ to $\mathrm{ET}_{1-21}$ are not fully known.

A lower baseline concentration could arise as part of a disease compensation mechanism-for example, local production of $\mathrm{ET}_{1-21}$ could be down regulated in response to the effects of fixed lumen obstruction of the digital artery; or to compensate for pre-existing distortions of vascular tone or the balance of EDRF and EDCF effects. It might also arise as part of a more widespread damage effect consequent on endothelial sheer stress. Arteriographic studies of occlusive change in the digital arteries of some patients ${ }^{2627}$ and the reported depletion of vasoactive peptides in the cutaneous nerve supply of others, ${ }^{17}$ provide supporting evidence for a damage effect.

The cold response of cases and controls is of considerable interest. An active mechanistic agent might be expected to show the pattern described-that is, a rise in response to cold greater in cases than controls and more noteworthy again in the worst cases and especially in those men with vasospasm. However, these findings need to be interpreted cautiously, as again the situation may be more complex than at first appears. Zamora et al showed a similar response in primary Raynaud's phenomenon but not until an $80 \%$ decrement in pulsatility had already occurred (they postulated that $\mathrm{ET}_{1-21}$ was a player but not a prime mover in the vasospasm found). ${ }^{15}$

Workers have questioned whether the rise found by Zamora et al could be explained by haemoconcentration or altered forearm blood flow. ${ }^{20}$ In the present study concentrations of serum albumin and von Willebrand's factor were also measured at baseline and after cold challenge. The mean (SEM) percentage change in serum albumin was similar in cases $(-1.9 \% \quad(1.8 \%))$ and controls $(-2.1 \%$ $(2 \cdot 0 \%)$ in exposed controls; $2 \cdot 8 \%(1.6 \%)$ in pure controls), so haemoconcentration does not explain the large relative rise in $E_{1-21}$ among patients. However, it is more difficult to discount the effects of forearm blood flow. Measurements of $\mathrm{ET}_{1-21}$ in venous and arterial blood have shown that the forearm is a site of ET production, ${ }^{28}$ so the notable fall in blood flow that accompanies vasospasm could create the impression of raised local production artifactually. In our data set the mean (SEM) percentage changes in the VWF, which is produced by the endothelium, were not significantly different between cases and controls $(+0.4 \%(8 \cdot 7 \%)$ for cases, $-4.7 \%(5 \cdot 7 \%)$ for pure controls, and $-4 \cdot 1 \%(9.5 \%)$ for exposed controls), lending tentative support to the view that forearm blood flow does not account for the changes found. However, this question needs to be considered by further work encompassing specific measurements of forearm blood flow or measurements in $\mathrm{ET}_{1-21}$ in both venous and arterial blood. Forearm blood flow is an important unknown quantity in interpreting the present data.

The clinical pattern found in the blanching group in this study was decidedly heterogeneous: in some cases blanching was immediate and brief; in others it developed a few minutes after cold challenge; and one quarryman had almost permanent blanching reversed briefly by cold challenge!

This may be reflected in the wide variation in measured $\mathrm{ET}_{1-21}$ in individual cases, with rises of more than $300 \%$ in some, falls in others, and stable values in some men found to blanch. The $\mathrm{ET}_{1-21}$ alone is not a complete explanation of blanching.

It is worth noting in the context of this clinical diversity of response that the SD for percentage change in $\mathrm{ET}_{1-21}$ is almost twice as great in cases as controls. The probability that a difference as large as this arises by chance alone is less than 0.01 and may reflect the rela- 
tively greater instability of $\mathrm{ET}_{1-21}$ concentrations (or forearm blood flow) after cold challenge in cases.

Given the significant associations found in this study it is tempting to hypothesise that $\mathrm{ET}_{1-21}$ has a role in the vascular manifestations of VWF: that baseline ET $_{1-21}$ concentrations adjust in circumstances of warm equilibration to compensate for the disease process and that an unstable, but generally exaggerated production of $\mathrm{ET}_{1-21}$ is implicated directly or indirectly in cold vasospasm. However, the possibility that the associations described measure effect rather than cause, cannot fully be discounted and needs further work.

Several avenues could be fruitful. Measurement of $\mathrm{ET}_{1-21}$ binding to its receptors could be used to identify the effective local concentrations at sites of vasospasm, rather than in the venous overspill as at present. Further histochemical work and the use of recently developed ET receptor blockers may enable a more specific exploration to take place. The ultimate test of the significance of $\mathrm{ET}_{1-21}$ in VWF may be judged from the therapeutic impact of ET blockage on this industrial complaint and its natural disease counterparts.

We acknowledge the assistance of members of the Employment Medical Advisory Service team from the Area South office and of colleagues from the Health and Safety Laboratory, who undertook the novel assays that form the cornerstone of this report. Helpful advice was also received from the HSE's Research Advisory Team and Drs Crane, Coggon, McCaig, and Noble: we thank them.

1 Loriga G. Il Lavorco co i martelli pneumatici? Boll Inspett Lavoro 1911;2:35-60.

2 Griffin MJ. The effects of vibration on health. Southampton: University of Southampton Institute of Sound and Vibration Research, 1982. (Memorandum 632.)

3 Nerem RM. Vibration-induced arterial shear stress. The relationship to Raynaud's phenomenon of occupational origin. Arch Environ Health 1973;26:105-10.

4 Ikehata K, Kawauchi S, Kohno F, Nishiyama M, Ide N. Increased platelet function and von Willebrand factor in vibration syndrome. $\mathcal{F}$ Exp Med 1980;27:23-8.

5 Okada A, Ariizumi M, Fujinaga H. Diagnosis of the vibration syndrome by blood viscosity. In: Brammer AJ, Taylor $\mathrm{W}$, eds. Vibration effects on the hand and arm in industry. New York: John Wiley, 1982: 67-70.

6 Polanowska R, Cierniewski CS. Activation of blood platelets and increased plasma fibrinogen and fibronection in men exposed to infrasounds, acoustic noise and tion in men exposed to infrasounds, acoustic noise and airborne dust in

7 Furchgott RF, Zawadzki JV. The obligatory role of endothelial cells in the relaxation of arterial smooth muscle by acetylcholine. Nature 1980;288:373-6.
8 O'Brien R, Robbins RJ, McMurty IF. Endothelial cells in culture produce a vasoconstrictor substance. $\mathcal{F}$ Cell Physiol 1987;135:263-70.

9 Yanagisawa M, Kurihara H, Kimura S, Tomobe Y, Kobayaski M, Mitsui $\mathrm{Y}$, et al. A novel potent vasoconstrictor peptide produced by vascular endothelial cells. strictor peptide produced
Nature 1988;322:411-5.

10 Fyhrquist F, Saijonmaa O, Mertarinne K, Tikkanen I, Rosenlof K, Tikkanen T. Raised plasma endothelin-1 concentration following cold pressor test. Biochem Biophys Res Commun 1990;169:217-21.

11 Tomita K, Ujiie K, Nakanishi T, Tomuras S, Matsuda $O$, Ando K. Plasma endothelin levels in patients with uraemia. $N$ Engl f Med 1989;321:1127.

12 Salminen $K$, Tikkanen I, Saijonmaa O, Nieminen $M$, Fyhrquist F, Frick MH. Modulation of coronary artery tone in acute myocardial infarction by endothelin. Lancet 1989;ii:747.

13 Takahashi K, Ghatei MA, Lam H-C, Halloran DJO, Bloom SR. Elevated plasma endothelin in patients with Bloom SR. Elevated plasma endothelin in patien
diabetes mellitus. Diabetologia 1989;33:306-10.

14 Masaoka H, Suzuki R, Hirata Y, Emori T, Marumo F, Hirakawa K. Raised plasma endothelin in aneurysmal subarachnoid haemorrhage. Lancet 1989;ii:1402.

15 Zamora MR, O'Brien RF, Rutherford RB, Weil JV. Serum endothelin-1 concentrations and cold provocation in primary Raynaud's phenomenon. Lancet 1990;336:1144-7.

16 Kanno K, Hirata Y, Emori T, Ohtak K, Shichiri M, Shinohara $S$, et al. Endothelin and Raynaud's phenomenon. Ann F Med 1991;90:130-1.

17 Goldsmith PC, Molina FA, Bunker CB, Terenghi G, Leslie TA, Fowler CJ, et al. Cutnaeous nerve depletion in vibration-induced white finger. $₹$ Royal Soc Med 1994;87: tion-ind $377-81$.

18 McKenna K, McGrann S, Blann AD, Allen JA. An investigation into acute vascular effects of riveting. $\mathrm{Br} \mathcal{F}$ Ind $\mathrm{Med}$ 1993;50:160-6.

19 Davenport AP, Ashby MJ, Easton P, Ella S, Bedford J, Dickerson $C$, et al. A sensitive immunoassay measuring endothelin-like immunoreactivity in human plasma: comparison of levels in patients with essential hypertension and normotensive control subjects. Clin Sci 1990; 78:261-4.

20 Smits P, Hofman H, Rosmalen F, Wollersheim H, Thien $T$. Endothelin-1 in patients with Raynaud's phenomenon. Lancet $1991 ; 337: 1236$.

21 Ekenvall L, Lindblad L-E. Vibration-induced white finger and digital systolic pressure during cooling. $\mathrm{Br} \mathcal{F}$ Ind Med $1986 ; 43: 280-3$.

22 Griffin MJ. Handbook of human vibration. London: Academic Press, 1990: 573-5.

23 Gemne G, Pyykko I, Taylor W, Pelmear PL. The Stockholm workshop scale for the classification of coldinduced Raynaud's phenomenon in the hand-arm vibration syndrome (revision of the Taylor Pelmear scale) Scand $\mathcal{F}$ Work Environ Health 1987;13:275-8.

24 Emori T, Hirata Y, Ohta K, Shichiro M, Shimokadok K, Marumo F. Concomitant secretion of big endothelin and its C-terminal fragment from human and bovine its C-terminal fragment from human and bovine
endothelial cells. Biochem Biophys Res Commun 1989;162: 217-23.

25 Yang Z, Yang ZH, Richard V, von Segesser L. Threshold concentrations of endothelin-1 potentiate contractions to norepinephrine and serotonin in human arteries. Circulation 1990;82:188-95.

26 Tomasini T, Chiappino G, Castano P, Ambrosini A. Le lesioni vascolari da strumenti vibranti. Med Lav 1972;63 332-51

27 James PB, Galloway RW. Arteriography of the hand in men exposed to vibration. In: Taylor W, Pelmear PL, eds. Vibration white finger in industry. Chapter 4. London: Academic Press, $31-41$.

28 Wagner OF, Nowotry $P$, Vierhapper $H$, Waldhausl W Plasma concentrations of endothelin in man: arteriovenous differences and release during venous stasis. Eur $\mathcal{f}$ Clin Invest 1990;20:502-5. 